\title{
Fatal Case of Rhabdomyolysis Post-COVID-19 Vaccine
}

\author{
Kunal M Ajmera \\ Department of Hospital Medicine, \\ Calvert Health Medical Center, Prince \\ Frederick, MD, USA
}

\begin{abstract}
Severe acute respiratory syndrome coronavirus 2 (SARS-CoV-2) or COVID-19 pandemic has taken away the lives of many people ( $>4$ million per WHO) around the world as of July 2021. With the advancement of the vaccine against COVID-19, in less than a year since the start of the pandemic, the infection rate has come under control in certain regions but is still rising in many more. However, with time, we are also learning a lot more about the adverse events related to the vaccine. This report documents the first fatal case of rhabdomyolysis potentially associated with the COVID-19 vaccine and supports the possibility that autoimmunity is a major risk factor for covid vaccine-related rhabdomyolysis.
\end{abstract}

Keywords: rhabdomyolysis, COVID-19 vaccines, autoimmune disorders

\section{Introduction}

Severe acute respiratory syndrome coronavirus 2 (SARS-CoV-2), the cause of the COVID-19 pandemic, has affected the lives of most individuals worldwide. Global economic, financial, and political burdens have been enormous. According to the World Health Organization (WHO) and Centers for Disease Control (CDC) data tracker, since January 2020, there have been more than 194 million cases globally ${ }^{1}$ and more than 33 million cases in the US, ${ }^{2}$ with over 4 million deaths globally ${ }^{1}$ and 600,000 in the US as of July 2021. ${ }^{2}$ California, Texas, Illinois, and Florida are heavily affected. Developing a vaccine within 1 year of the beginning of the pandemic indicates how far novel technologies have advanced. To date, 203 million people have received at least one dose, and 172 million people, or approximately $52 \%$ of the US population, had been fully vaccinated as of August 2021. ${ }^{3}$ COVID-19 vaccines have effectively curbed the infection rate. However, with the increasing spread of variant strains (such as the delta variant), infection rates, hospitalizations, and deaths have rebounded, particularly among the unvaccinated. ${ }^{2,4}$

The currently available and most commonly administered vaccines in the US are two mRNA vaccines, Pfizer-BioNTech (BNT162b2) ${ }^{2}$ and Moderna (mRNA-1273), ${ }^{5}$ and the Janssen vaccine made of modified DNA of adenovirus (Johnson \& Johnson). ${ }^{6}$ The vaccines are approved for the age group 18 to 55 years. $^{7}$ Commonly reported adverse effects of vaccination are injection site pain and redness or swelling, fatigue, headache, muscle ache, and fever/chills. ${ }^{8}$ The current most common contraindications to vaccines listed on the CDC website are severe allergic reactions (eg, anaphylaxis) or immediate allergic reactions of any severity to the vaccine or its components. ${ }^{8}$
Correspondence: Kunal M Ajmera Calvert Health Medical Center, 100 Hospital Road, Prince Frederick, MD, 20678, USA

Tel + I 3/2-806-0353

Email kunalajmera@gmail.com 
Rhabdomyolysis is a clinical and laboratory syndrome resulting from an injury to skeletal muscles that results in myocyte destruction and the release of myoglobin, electrolytes, proteins (eg, CPK, aldolase, and LDH), and other toxic substances into circulating blood. In the kidneys, high concentrations of myoglobin can cause renal tubular obstruction and lead to renal failure. ${ }^{9}$

A literature review found two case reports describing patients with rhabdomyolysis post-COVID vaccine administration in the US. One patient was a young, otherwise healthy male who developed rhabdomyolysis post-PfizerBioNTech vaccine. ${ }^{10}$ The second case was an 80 -year-old man with diabetes who suffered rhabdomyolysis postModerna vaccine. ${ }^{11}$ One case of rhabdomyolysis was also reported post-AstraZeneca vaccine in the UK in April 2021. ${ }^{12}$ Here, the case of a patient who became severely ill with rhabdomyolysis and renal failure postsecond dose Moderna vaccine is presented.

\section{Methods}

A systematic review of medical literature with the keywords "rhabdomyolysis," "covid-19 vaccine," "autoimmune disorders," was performed on three databases: PubMed, Google Scholar, and ScienceDirect databases. Articles that included definition, pathophysiology, mechanism of action, etiology, and treatment were identified. All types of articles, including reviews (narrative and systematic), meta-analysis, literature review, randomized controlled trials (RCTs), case-control cohorts, case series, and case reports were screened for relevant content. Out of many articles found, 25 relevant articles were used in this paper in addition to data obtained from the CDC/WHO website. Pertinent information was summarized and organized for ease of understanding.

\section{Case Presentation}

Our patient was an 85-year-old Caucasian woman, a homemaker, with a medical history of rheumatoid arthritis, hyperlipidemia, and asthma who was recently diagnosed with a cerebrovascular accident (CVA) 2 months prior. She came to the emergency room (ER) 2 days after receiving the second dose of the MODERNA COVID-19 vaccine with generalized weakness, muscle cramps, and loss of appetite. The patient had received the first dose of the MODERNA vaccine 30 days before receiving the second dose. The patient tolerated the first dose well, except for minor pain at the injection site. However, the patient started to feel weak the same afternoon after receiving the second dose. Later, she went to use the bathroom and could not stand up from the toilet seat. Her husband helped her get to bed. Since then, she mostly stayed in bed except while using the bathroom with assistance.

The patient completely lost her appetite and experienced nausea, without any vomiting/diarrhea. Moreover, the patient noticed her urine color changing from dark brown to black on the same day of receiving the vaccination. The next day, her weakness worsened along with abdominal and muscle cramps, and she was brought to the ER by ambulance. The patient's home medications included clopidogrel, metoprolol, nifedipine, rosuvastatin, telmisartan, tofacitinib, and trazodone. Clopidogrel and trazodone were started about 2 months prior to admission when the patient had a stroke. All other medications were long term. There was no increase in the statin dose during the previous admission either. For the past 2 months, the patient was undergoing professional physiotherapy once a week and did non-weight bearing exercises at home daily for an hour, as advised by the therapist. Family history was positive for autoimmune disease in maternal grandmother. The patient had no previous history of tobacco or alcohol abuse. The patient had never contracted COVID-19 prior to this admission. There was no recent history of trauma or surgery. She had also not started to use any over-the-counter medications recently. The pertinent positives on the physical exam were the patient appearing exhausted without gross motor sensory deficits on admission, hypoactive bowel sounds, and generalized mild abdominal tenderness to superficial and deep palpation. The patient was alert and oriented to time, place, and person. Her vital signs remained stable, and the blood work on admission showed significantly elevated serum creatinine of $6.0 \mathrm{mg} / \mathrm{dL}$ (normal range: $0.6-1.3 \mathrm{mg} / \mathrm{dL}$ ), blood urea nitrogen (BUN) of $73 \mathrm{mg} / \mathrm{dL}$ (normal range: 7$18 \mathrm{mg} / \mathrm{dL}$ ) and significantly decreased glomerular filtration rate (GFR) of $6 \mathrm{~mL} / \mathrm{min}$ (normal range: $>60 \mathrm{~mL} / \mathrm{min}$ ) and bicarbonate of $13 \mathrm{mmol} / \mathrm{L}$ (normal range: $21-32 \mathrm{mmol} / \mathrm{L}$ ). The patient also had abnormally elevated liver function with aspartate aminotransferase (AST) of $1422 \mathrm{U} / \mathrm{L}$ (normal range: $15-37 \mathrm{U} / \mathrm{L}$ ), alanine aminotransferase (ALT) of $600 \mathrm{U} / \mathrm{L}$ (normal range: 15-37 U/L), and alkaline phosphatase of $600 \mathrm{U} / \mathrm{L}$ (normal range: 45-117 U/L). Her creatine phosphokinase (CPK) level was found to be extremely elevated at $>14,000 \mathrm{U} / \mathrm{L}$ (normal range: $26-192 \mathrm{U} /$ L). Troponin levels were $0.18 \mathrm{ng} / \mathrm{mL}$ (normal range: 0.00 $0.04 \mathrm{ng} / \mathrm{mL}$ ), followed by $0.21 \mathrm{ng} / \mathrm{mL}$ and $0.20 \mathrm{ng} / \mathrm{mL}$. 
Urinalysis was positive for $3+$ blood, negative for red blood cells (RBCs), and showed $>5000 \mathrm{mcg} / \mathrm{mL}$ myoglobin. Non-contrast enhanced computed tomography (CT) of the abdomen and head revealed no acute finding.

Further investigation revealed an aldolase level of 353 $\mathrm{U} / \mathrm{L}$ (normal range: $<7.7 \mathrm{U} / \mathrm{L}$ ), but it was falsely elevated due to hemoglobin contamination secondary to hemolysis. The patient was started on bicarbonate-rich intravenous fluids; however, we were not able to aggressively hydrate the patient, because she was also found to have heart failure with preserved ejection fraction $(\mathrm{HFpEF})$ in exacerbation (pro-BNP: $1388 \mathrm{pg} / \mathrm{mL}$ on admission followed by $6260 \mathrm{pg} / \mathrm{mL}$ upon recheck; normal range: 5-450 pg/mL). An echocardiogram showed an ejection fraction of 55 $60 \%$ with diastolic dysfunction. Table 1 compares the results of the patient's laboratory tests on the day of admission versus the last day of hospitalization. Figures 1 and 2 are graphical presentations of data.

Over the course of hospitalization, the patient became progressively weaker to a point where she could not even lift/move her hands or legs. Mentation started to decline, with patient intermittently getting confused or experiencing hallucinations. She developed $3+$ pitting edema over the bilateral upper and lower extremities. The disease course was further complicated when a chest CT showed complete consolidation and volume loss of the right lower lobe, partial consolidation and volume loss of the left lower lobe, mild ascites, and moderate anasarca. The patient was started on broadspectrum intravenous antibiotics. An urgent temporary dialysis catheter was inserted and the patient subsequently received hemodialysis secondary to hypoxia from pleural effusion/anasarca and oliguria/renal failure. After neurological evaluation, the patient was started on empiric glucocorticoids owing to concerns of myositis, secondary to no improvement in her strength. Cerebrospinal fluid (CSF) analysis revealed a clear appearance, with cultures remaining negative. Table 2 shows the complete CSF analysis results.

Subsequently, the patient was transferred to the intensive care unit, initially on bilevel positive airway pressure/ intermittent high-flow oxygen, but later intubated on ventilator support. The CPK levels continued to remain higher than the normal limit at $>14,000 \mathrm{U} / \mathrm{L}$. The patient ultimately had a cardiac arrest with subsequent fixed and dilated pupils causing suspicion of hypoxic/anoxic brain injury. After palliative care consultation, the patient's family decided it was best to increase the patient's comfort and care. The patient was terminally extubated and died the same day.

\section{Discussion}

Rhabdomyolysis is a potentially fatal syndrome with a high mortality rate. Common etiologies include alcohol abuse, muscle overexertion, muscle compression, medication, change in body temperature (heat-related), ischemia, infectious agents (viruses such as parainfluenza and CMV and bacteria such legionella, staphylococcus, and listeria), inflammation, metabolic myopathies, and genetic factors. $^{13,14}$ Often, patients present with signs and symptoms of myalgias, muscle weakness, and hematuria (teacolored urine). ${ }^{15}$

Change in urine color occurs because of an increase in myoglobin levels, usually in excess of $250 \mu \mathrm{g} / \mathrm{mL}$ (normal $<5 \mathrm{ng} / \mathrm{mL}) .{ }^{16,17}$ Kidney injury is the most common and potentially life-threatening complication of rhabdomyolysis that may require continuous renal replacement therapy or hemodialysis if not treated appropriately. ${ }^{13}$ The severity of renal failure is directly proportional to urine myoglobin $^{18}$ and $\mathrm{CPK}^{19}$ concentrations. The proposed mechanisms of renal failure in rhabdomyolysis are renal tubular obstruction due to myoglobin concentration in kidneys, free radical-mediated cytotoxicity causing tubular necrosis, and renal vasoconstriction in response to an extracellular fluid shift to traumatized muscles. ${ }^{20}$ Mortality rate increases further as patients develop renal failure and require dialysis (as high as 59\% in critically ill patients) or associated sepsis, compartment syndrome, or neuroleptic malignant syndrome. ${ }^{19,21}$ Guidelines on treatment and management of rhabdomyolysis are mainly focused on volume expansion with aggressive intravenous fluid hydration remaining the main line of treatment.

Vaccines have been used as a primary disease prevention measure for centuries. Most adverse events caused by vaccines are acute, transient, and not life-threatening. Because of the rapid advancement in COVID-19 vaccines, data are currently limited to near-term and long-term adverse events. According to the CDC Vaccine Adverse Event Reporting System, as of July 26, 2021, ${ }^{22}$ a total of 111 (60 males, 47 females, 4 unknown) cases of rhabdomyolysis have been reported post-COVID-19 vaccine, including five deaths.

According to a case report by Nassar et al, ${ }^{10}$ the patient was young (age 21) and had received only one dose of the Pfizer-BioNTech COVID-19 vaccine before developing rhabdomyolysis. However, the patient had a medical 
Table I Blood Work Results During Hospitalization

\begin{tabular}{|c|c|c|c|}
\hline & $\begin{array}{l}\text { Blood Work on the Day of } \\
\text { Admission }\end{array}$ & $\begin{array}{l}\text { Blood Work on the Last Day of } \\
\text { Hospitalization }\end{array}$ & Normal Range \\
\hline WBC & 7.6 & 19.7 & $4.0-11.0$ UNIT- $10 \times 3$ uL \\
\hline RBC & 4.17 & 1.45 & $4.0-5.50 .10 \times 6 / u L$ \\
\hline Hemoglobin & 12.4 & 4.4 & $11.0-16.0 \mathrm{~g} / \mathrm{dL}$ \\
\hline Platelet & 203 & 134 & $150-450.10 \times 3 / u L$ \\
\hline Sodium & 134 & 153 & $136-145 \mathrm{mmol} / \mathrm{L}$ \\
\hline Potassium & 4.6 & 6 & $3.5-5.1 \mathrm{mmol} / \mathrm{L}$ \\
\hline $\mathrm{CO} 2$ & 13 & 39 & $21-32 \mathrm{mmol} / \mathrm{L}$ \\
\hline Anion gap & 19 & 20 & $8-16 \mathrm{mEQ} / \mathrm{L}$ \\
\hline BUN & 21 & 61 & $7-18 \mathrm{mg} / \mathrm{dL}$ \\
\hline S. Creatinine & 6 & 2.7 & $0.6-1.3 \mathrm{mg} / \mathrm{dL}$ \\
\hline GFR & 6 & 16 & $>60 \mathrm{~mL} / \mathrm{min}$ \\
\hline Lactic acid & 1.3 & 19.3 & $0.4-2.0 \mathrm{mmol} / \mathrm{L}$ \\
\hline Calcium & 8.4 & 5.3 & $8.5-10.1 \mathrm{mg} / \mathrm{dL}$ \\
\hline Phosphorus & 7.2 & 10.3 & $2.5-4.9 \mathrm{mg} / \mathrm{dL}$ \\
\hline T. Bilirubin & 0.3 & 0.6 & $0.2-1.0 \mathrm{mg} / \mathrm{dL}$ \\
\hline AST & 1422 & 2066 & $15-37 \mathrm{U} / \mathrm{L}$ \\
\hline ALT & 600 & 1746 & I2-78 U/L \\
\hline CPK & $>14,000$ & $>14,000$ & $26-192 \mathrm{U} / \mathrm{L}$ \\
\hline CRP & 74.0 & 17.8 & $<3.0 \mathrm{mg} / \mathrm{L}$ \\
\hline Troponin & 0.18 & 0.88 & $0.0-0.04 \mathrm{ng} / \mathrm{mL}$ \\
\hline proBNP & 1388 & 5391 & $5-450 \mathrm{pg} / \mathrm{mL}$ \\
\hline ESR & 28 & & $0-30 \mathrm{~mm} / \mathrm{Hr}$ \\
\hline $\begin{array}{l}\text { Carnitine level (Total and } \\
\text { free) }\end{array}$ & Wnl & & \\
\hline
\end{tabular}

Abbreviations: WBC, White blood cell; RBC, Red blood cell; CO2, Bicarbonate; BUN, Blood Urea Nitrogen; GFR, Glomerular Filtration Rate; AST, Aspartate aminotransferase; ALT, Alanine aminotransferase; CPK, Creatine kinase; CRP, C-reactive protein; proBNP, NT-Pro-B-Natriuretic Peptide; ESR, Erythrocyte sedimentation rate.

history of asthma, which is considered an autoimmune disease $^{23}$ or hyperactive/overactive immune disease. ${ }^{24}$ There was no family history of autoimmune conditions. In a case published by Mack et al, ${ }^{11}$ the patient was 80 years old and developed rhabdomyolysis after a second dose of the Moderna vaccine. There was no mention of any family history in the report, and the patient contracted COVID-19 infection 3 months before receiving the vaccine. The patient was subsequently treated with dexamethasone/remdesivir and convalescent plasma. The patient was also an insulin-dependent type II diabetic. The role of TNF- $\alpha$ and other pro-inflammatory cytokines is well documented in dysregulating insulin production and sensitivity ${ }^{25,26}$ in people with insulin-dependent diabetes mellitus (IDDM), among many other mechanisms. In the case published by Tan et $\mathrm{al},{ }^{12}$ the male patient who developed rhabdomyolysis was uniquely different and was deficient in carnitine palmitoyltransferase II (a neuromuscular disorder). According to the current study, female patient had been on a statin for many years, a known risk factor for rhabdomyolysis. The patient also had rheumatoid arthritis, an autoimmune disorder, and a family history of autoimmune disease.

Rhabdomyolysis is a well-known complication of both early and late COVID-19 infection. ${ }^{27,28}$ The proposed mechanisms for virus-induced muscle destruction include direct toxic effects of viruses on cells and cytokineinduced muscle damage. ${ }^{29,30}$ How and why some patients develop rhabdomyolysis post-COVID-19 vaccine are not well understood. A blood test is currently not available that can establish a direct causal link. Pfizer-BioNTech and Moderna vaccines code only a part of a single protein on the virus to stimulate the immune response. ${ }^{5}$

The messenger RNA in mRNA vaccines enters the host cytoplasm and begins producing surface spike proteins. These proteins are ultimately presented to antigenpresenting cells, producing immune responses/antibodies against the actual virus. An mRNA vaccine also induces $\mathrm{CD} 4+$ and $\mathrm{CD} 8+\mathrm{T}$ cell responses. ${ }^{31} \mathrm{CD} 4+\mathrm{T}$ cells induce cytokine production, whereas the response of $\mathrm{CD} 8+$ 
80

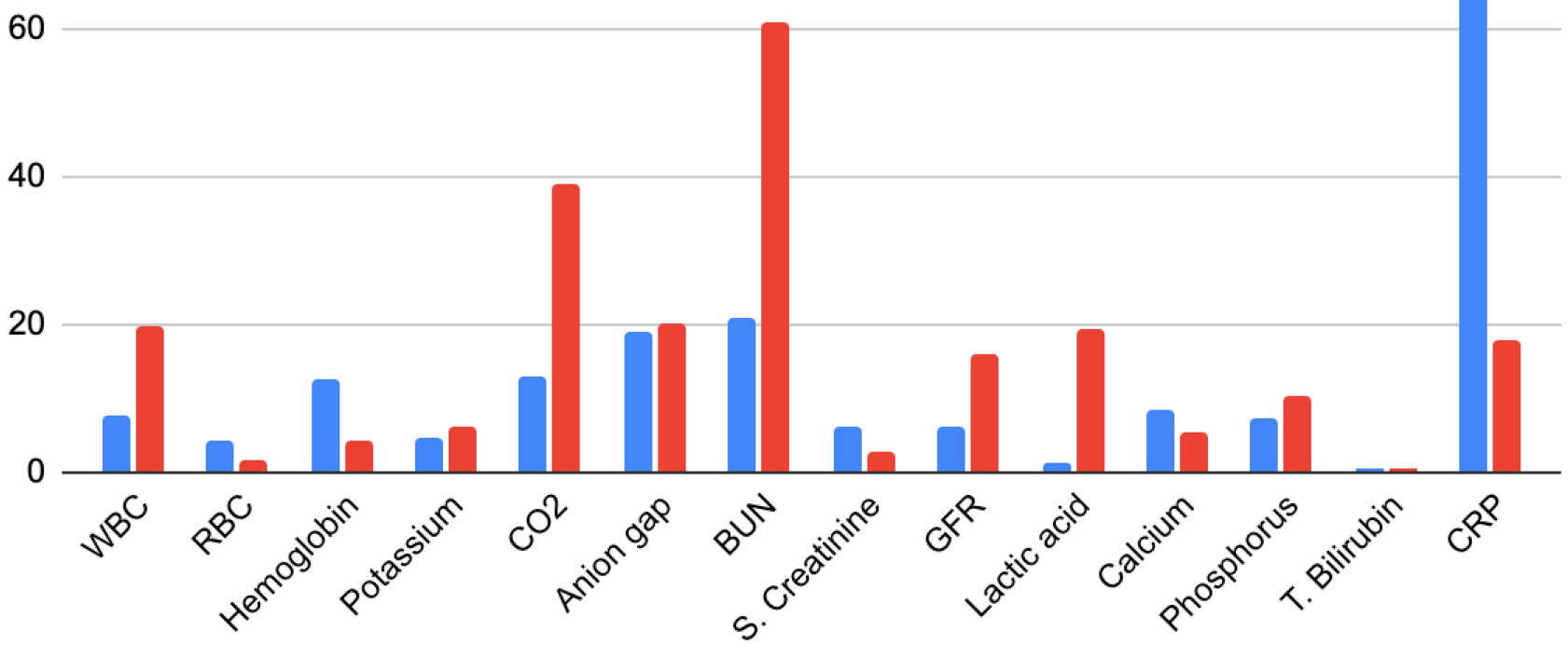

Figure I Blood work on the day of admission and blood work on the last day of hospitalization.

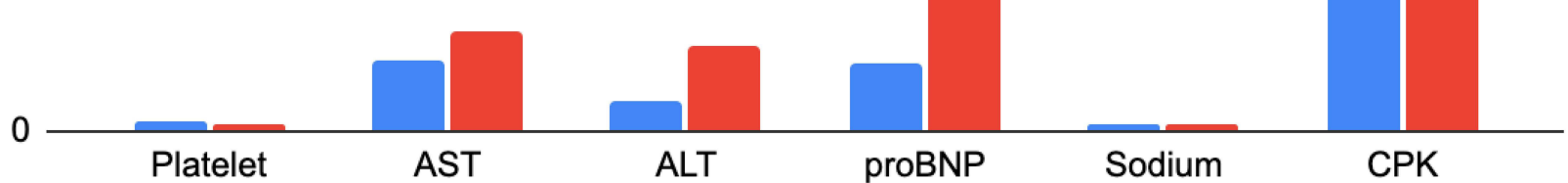

Figure 2 Blood work on the day of admission and blood work on the last day of hospitalization.

$\mathrm{T}$ cells is directed against the viral spike protein, which helps remove the virus from the intracellular compartment. ${ }^{32}$
In autoimmune disorders, the immune system is hyperactive or dysregulated and attacks itself. ${ }^{33}$ There is compelling evidence for dysregulated $\mathrm{T}$ cells in rheumatoid 
Table 2 CSF Results

\begin{tabular}{|l|r|c|}
\hline CSF Analysis & & Reference Range \\
\hline WBC & 2 & $(0-5 / \mathrm{cu} \mathrm{mm})$ \\
RBC & 2 & $(0 . \mathrm{cu} \mathrm{mm})$ \\
Glucose & 73 & $(40-70 \mathrm{mg} / \mathrm{dL})$ \\
Total protein & 31.6 & $(15-60 \mathrm{mg} / \mathrm{dL})$ \\
Myelin Basic Protein & 8.7 & $(0.0-5.6 \mathrm{ng} / \mathrm{mL})$ \\
VDRL & Negative & \\
Herpes I/II & Negative & \\
West Nile & Negative & \\
\hline
\end{tabular}

Abbreviations: CSF, cerebrospinal fluid; WBC, white blood cell; RBC, red blood cell; VDRL, venereal disease research laboratory test.

arthritis, ${ }^{34}$ and it is possible the dysregulated immune system is overstimulated by vaccine and begins to attack the body's cells. Further investigations are needed in patients with autoimmune diseases (active disease vs inactive disease) to determine whether they can mount adequate immune responses to the COVID-19 virus after the first dose only. If the immune response is adequate, the need for a second dose of a vaccine should be assessed because an unnecessary or inflammatory response is harmful to the host.

\section{Conclusion}

With the use of novel technologies to develop vaccines, a new era of vaccinology is beginning. In a time of crisis, such as the current COVID-19 pandemic, the availability of a vaccine with $>94 \%$ efficacy is a blessing. It is essential to screen such patients based on their age, medical and family histories of autoimmune disease, and home medications before administering a COVID-19 vaccine. Patients with known risk factors for rhabdomyolysis should be carefully monitored and screened before administering a vaccine. When a patient with known risk factors for rhabdomyolysis complains of generalized muscle aches/cramps or weakness post-vaccine, they should get prompt treatment without delay to prevent further complications. Currently, not enough data are available on the adverse event profile of the COVID-19 vaccines in patients with an autoimmune disorder and dysregulated immune system. Benefits vs risks certainly need to be assessed for the first dose only vs additional doses of a vaccine in this group.

\section{Ethics Approval and Informed Consent}

Ethics approval is not needed for this article. A case report is a medical activity that does not meet the DHHS definition of "research," which is: "a systematic investigation, including research development, testing and evaluation, designed to develop or contribute to generalizable knowledge." Therefore, the activity does not have to be reviewed by the IRB. Information/health data used in this article are HIPPA compliant. Informed consent was also obtained from the patient and the family for the publication of this case report.

\section{Acknowledgment}

Author thanks Dr Paul H. Levine for his helpful comments on the manuscript.

\section{Funding}

The author has not declared receiving any grant/funding for this research from any funding agency in the public, commercial, or not-for-profit sectors.

\section{Disclosure}

Author reports no conflicts of interest (financial or nonfinancial) in this work.

\section{References}

1. World Health Organization. Coronavirus (COVID-19) Dashboard. Available from: https://covid19.who.int. Accessed July 21, 2021.

2. United States COVID-19 cases, deaths, and laboratory testing (NAATs) by state, territory, and jurisdiction. Available from: https:// covid.cdc.gov/covid-data-tracker/?CDC_AA_refVal=https $\% 3 \mathrm{~A} \% 2 \mathrm{~F}$ $\% 2 \mathrm{Fwww}$.cdc.gov $\% 2 \mathrm{~F}$ coronavirus $\% 2 \mathrm{~F} 2019$-ncov $\% 2 \mathrm{~F}$ cases-updates \%2Fcases-in-us.html\#cases_totalcases. Accessed July 21, 2021.

3. COVID data tracker weekly review, CDC. Available from: https:// covid.cdc.gov/covid-data-tracker/\#vaccination-trends_vacctrendsfully-daily. Accessed August 21, 2021.

4. O'Dowd A. Covid-19: cases of delta variant rise by $79 \%$, but rate of growth slows. BMJ. 2021;373:n1596. doi:10.1136/bmj.n1596

5. Meo SA, Bukhari IA, Akram J, Meo AS, Klonoff DC. COVID-19 vaccines: comparison of biological, pharmacological characteristics and adverse effects of Pfizer/BioNTech and moderna vaccines. Eur Rev Med Pharmacol Sci. 2021;25(3):1663-1669. doi:10.26355/ eurrev_202102_24877

6. Livingston EH, Malani PN, Creech CB. The Johnson \& Johnson vaccine for COVID-19. JAMA. 2021;325(15):1575. doi:10.1001/ jama.2021.2927

7. Moderna COVID-19 vaccine questions. Available from: https://www. cdc.gov/vaccines/covid-19/info-by-product/moderna/moderna-faqs. html\#contraindications. Accessed July 20, 2021.

8. Different COVID-19 vaccines. Available from: https://www.cdc.gov/ coronavirus/2019-ncov/vaccines/different-vaccines.html. Accessed July 20, 2021.

9. Zager RA. Rhabdomyolysis and myohemoglobinuric acute renal failure. Kidney Int. 1996;49(2):314-326. doi:10.1038/ki.1996.48

10. Nassar M, Chung H, Dhayaparan Y, et al. COVID-19 vaccine induced rhabdomyolysis: case report with literature review. Diabetes Metab Syndr. 2021;15(4):102170. doi:10.1016/j. dsx.2021.06.007 
11. Mack M, Nichols L, Guerrero DM. Rhabdomyolysis secondary to COVID-19 vaccination. Cureus. 2021;13(5):e15004. doi:10.7759/ cureus. 15004

12. Tan A, Stepien KM, Narayana STK. Carnitine palmitoyltransferase II deficiency and post-COVID vaccination rhabdomyolysis [published online ahead of print, 2021 Apr 19]. QJM. 2021; hcab077. doi:10.1093/qjmed/hcab077

13. Sauret JM, Marinides G, Wang GK. Rhabdomyolysis. Am Fam Physician. 2002;65(5):907-912.

14. Chavez LO, Leon M, Einav S, Varon J. Beyond muscle destruction: a systematic review of rhabdomyolysis for clinical practice. Crit Care. 2016;20(1):135. doi:10.1186/s13054-016-1314-5

15. Bosch X, Poch E, Grau JM. Rhabdomyolysis and acute kidney injury [published correction appears in N Engl J Med. 2011 May 19;364(20):1982]. N Engl J Med. 2009;361(1):62-72. doi:10.1056/ NEJMra0801327.

16. David WS. Myoglobinuria. Neurol Clin. 2000;18(1):215-243. doi:10.1016/s0733-8619(05)70187-0

17. Warren JD, Blumbergs PC, Thompson PD. Rhabdomyolysis: a review. Muscle Nerve. 2002;25(3):332-347. doi:10.1002/mus.10053

18. Loun B, Astles R, Copeland KR, Sedor FA. Adaptation of a quantitative immunoassay for urine myoglobin. Predictor in detecting renal dysfunction. Am J Clin Pathol. 1996;105(4):479-486. doi:10.1093/ajcp/105.4.479

19. de Meijer AR, Fikkers BG, de Keijzer MH, van Engelen BG, Drenth JP. Serum creatine kinase as predictor of clinical course in rhabdomyolysis: a 5-year intensive care survey. Intensive Care Med. 2003;29(7):1121-1125. doi:10.1007/s00134-003-1800-5.

20. Holt SG, Moore KP. Pathogenesis and treatment of renal dysfunction in rhabdomyolysis. Intensive Care Med. 2001;27(5):803-811. doi:10.1007/s001340100878

21. McMahon GM, Zeng X, Waikar SS. A risk prediction score for kidney failure or mortality in rhabdomyolysis. JAMA Intern Med. 2013;173(19):1821-1828. doi:10.1001/jamainternmed.2013.9774

22. United States Department of Health and Human Services (DHHS), Public Health Service (PHS), Centers for Disease Control (CDC)/ Food and Drug Administration (FDA), Vaccine Adverse Event Reporting System (VAERS) 1990-4/16/2021, CDC WONDER on-line database; 2021. Available from: https://wonder.cdc.gov/ vaers.html. Accessed July 21, 2021.

23. Mukherjee M, Nair P. Autoimmune responses in severe asthma. Allergy Asthma Immunol Res. 2018;10(5):428-447. doi:10.4168/ aair.2018.10.5.428
24. Busse WW, Banks-Schlegel S, Wenzel SE. Pathophysiology of severe asthma. J Allergy Clin Immunol. 2000;106(6):1033-1042. doi:10.1067/mai.2000.111307

25. Scheen AJ. Pathophysiology of type 2 diabetes. Acta Clin Belg. 2003;58(6):335-341. doi:10.1179/acb.2003.58.6.001

26. Greenberg AS, McDaniel ML. Identifying the links between obesity, insulin resistance and beta-cell function: potential role of adipocyte-derived cytokines in the pathogenesis of type 2 diabetes. Eur J Clin Invest. 2002;32(Suppl 3):24-34. doi:10.1046/j.13652362.32.s3.4.x

27. Buckholz AP, Kaplan A, Rosenblatt RE, Wan D. Clinical characteristics, diagnosis, and outcomes of 6 patients with COVID-19 infection and rhabdomyolysis. Mayo Clin Proc. 2020;95(11):2557-2559. doi:10.1016/j.mayocp.2020.09.005

28. Valente-Acosta B, Moreno-Sanchez F, Fueyo-Rodriguez O, PalomarLever A. Rhabdomyolysis as an initial presentation in a patient diagnosed with COVID-19. BMJ Case Rep. 2020;13(6):e236719. doi:10.1136/bcr-2020-236719

29. Fodili F, van Bommel EF. Severe rhabdomyolysis and acute renal failure following recent Coxsackie B virus infection. Neth $\mathrm{J} \mathrm{Med}$. 2003;61(5):177-179.

30. Craighead JE, Huber SA, Sriram S. Animal models of picornavirus-induced autoimmune disease: their possible relevance to human disease. Lab Invest. 1990;63(4):432-446.

31. Sagili Anthony DP, Sivakumar K, Venugopal P, Sriram DK, George M. Can mRNA vaccines turn the tables during the COVID-19 pandemic? Current status and challenges [published correction appears in Clin Drug Investig. 2021 Jun 5]. Clin Drug Investig. 2021;41(6):499-509. doi:10.1007/s40261-021-01022-9

32. Pfizer and BioNTech provide data from German Phase 1/2 study further characterizing immune response following immunization with lead COVID-19 vaccine candidate BNT162b2. Pfizer. Available from: https://www.pfizer.com/news/press-release/pressrelease-detail/pfizer-and-biontech-provide-data-german-phase-12study. Accessed February 20, 2021.

33. Gibofsky A. Epidemiology, pathophysiology, and diagnosis of rheumatoid arthritis: a synopsis. Am J Manag Care. 2014;20(7 Suppl): S128-S135.

34. Cope AP, Schulze-Koops H, Aringer M. The central role of T cells in rheumatoid arthritis. Clin Exp Rheumatol. 2007;25(5 Suppl 46):S4S11.
Infection and Drug Resistance

\section{Publish your work in this journal}

Infection and Drug Resistance is an international, peer-reviewed openaccess journal that focuses on the optimal treatment of infection (bacterial, fungal and viral) and the development and institution of preventive strategies to minimize the development and spread of resistance. The journal is specifically concerned with the epidemiology of antibiotic resistance and the mechanisms of resistance development and diffusion in both hospitals and the community. The manuscript management system is completely online and includes a very quick and fair peerreview system, which is all easy to use. Visit http://www.dovepress.com/ testimonials.php to read real quotes from published authors. 